\title{
TERRITÓRIOS DE "VIDA" E DE "MORTE": UM OLHAR SOBRE OS CONFLITOS TERRITORIAIS ASSOCIADOS AO PARQUE NACIONAL DA SERRA DO CIPÓ, MG
}

\author{
TERRITORIES OF LIFE AND DEATH: \\ A LOOK ON TERRITORIAL CONFLICTS ASSOCIATED WITH \\ THE NATIONAL PARK OF SERRA DO CIPÓ, MG (BRAZIL) \\ TERRITORIOS DE “VIDA” Y DE “MUERTE”: \\ UNA MIRADA A CERCA DE LOS CONFLICTOS TERRITORIALES \\ ASOCIADOS AL PARQUE NACIONAL DA SERRA DO CIPÓ, MG \\ Altair Sancho Pivoto dos Santos - Universidade Federal de Juiz \\ de Fora - Juiz de Fora - Minas Gerais - Brasil \\ altair.sancho@uff.edu.br
}

\begin{abstract}
Resumo
0 Parque Nacional da Serra do Cipó (PARNASC), localizado na porção meridional da Serra do Espinhaço, região central do Estado de Minas Gerais, foi criado em 1984 sob as justificativas de preservação de espécies endêmicas, proteção da bacia de captação do rio Cipó e de paisagens com grande potencial ao desenvolvimento turístico. Apesar das contribuições inequívocas à conservação da biodiversidade do Espinhaço, tal iniciativa foi norteada por uma lógica unidirecional e unilateral de proteção, responsável por imprimir novos regramentos aos usos (i)materiais então coexistentes na Serra do Cipó, inclusive o impedimento da permanência de moradores em territórios historicamente ocupados. Diante desse contexto, o presente trabalho se volta para uma situação específica de conflito territorial, envolvendo a desterritorialização de uma família de agricultores tradicionais em virtude da implantação do PARNASC. Procurou-se, nessa direção, compreender como se efetivou tal processo, bem como as repercussões nos exercícios de territorialidade dos integrantes dessa família. Ancorado em um viés qualitativo, a presente pesquisa envolveu pesquisa bibliográfica e documental, além de entrevistas com analistas do Instituto Chico Mendes de Conservação da Biodiversidade (ICMBio) e com membros da família "Miné". Os resultados indicam que essa família foi expulsa de suas terras, sem direito à defesa e aguardam até hoje a resolução desse conflito.

Palavras-chave: Unidades de conservação, parque, conflito territorial, Serra do Cipó.
\end{abstract}

\section{Abstract}

The Serra do Cipó National Park (PARNASC, acronym in Portuguese), located in the southern part of the Espinhaço Mountain Range, central region of the State of Minas Gerais, Brazil, was created in 1984 with the justification of preserving endemic species, protection of the Rio do Cipó's watershed, as well as protecting landscapes with great potential for touristic development. In spite of the unequivocal contributions to the preservation of biodiversity in the Espinhaço region, such initiative was guided by a unidirectional and unilateral rationale of protection, responsible for creating new rules for the immaterial uses then coexisting in the Cipó Mountain Range, including the removal of inhabitants in historically occupied territories. In this context, this study focuses on a specific situation of territorial conflict, involving the dislodging of a family of traditional farmers due to the implementation of the National Park. We seek to understand how this process came to be, as well as the repercussions in the exercises of territoriality of the members of this family. Based on a qualitative method, this research involved bibliographical and documental research, as well as interviews with 
analysts from ICMBio and members of the "Miné" family. The results indicate that this family was removed from their land, without due process and await, until today, a solution for this conflict.

Keywords: Conservation units, park, territorial conflict, Cipó Mountain Range.

\section{Resumen}

El Parque Nacional da Serra do Cipó (PARNASC), ubicado en la porción meridional de la Sierra de Espinhaço, región central de Estado de Minas Gerais, fue criado en 1984 con las justificativas de preservación de las especies endémicas, protección de la bacía del rio Cipó y de paisajes con un gran potencial al desarrollo turístico. Pesar de las contribuciones innegables a la conservación de la biodiversidad de Espinhaço, esta acción fue norteada por una lógica unidireccional y unilateral de protección, responsable por ofrecer nuevos ordenamientos territoriales a los usos i-materiales coexistentes en la Serra do Cipó, incluso el impedimento de la permanencia de los moradores en territorios históricamente ocupados. En este sentido, el presente trabajo vuelve a sus atenciones para una situación específica de conflicto territorial, lo que implica la desterritorialización de una familia de agricultores tradicionales en consecuencia de la implementación de PARNASC. Se buscó, en esa dirección, comprender como se ha efectuado tal proceso y también las repercusiones en los ejercicios de territorialidad de los integrantes de esa familia. Basado en un método cualitativo de investigación, la presente investigación envolvió pesquisa bibliográfica y documental, y también entrevistas con analistas del ICMBio y con miembros de la familia "Miné". Los resultados apuntan que esa familia fue expulsada de sus tierras, sin directo a la defensa y esperan hasta hoy la resolución de ese conflicto. Palabras clave: Unidades de conservación, parque, conflicto territorial, Serra do Cipó.

\section{Introdução}

A partir da segunda metade do século XX, teve início o processo de institucionalização do meio ambiente, que culminou com a construção de uma nova ordem ambiental (Diegues, 1994; Bryant; Bailey, 1997). Na esteira desse movimento, a criação de áreas protegidas passou a adquirir relevância em âmbito internacional, resultado de um conjunto de medidas políticas e iniciativas que buscaram ratificar uma visão particular de proteção da natureza - por meio de tratados, congressos, acordos, convenções em praticamente todos os países. Seguindo tal tendência, desde então, o Brasil vem aprimorando seu arcabouço legal e as estratégias voltadas à proteção de sua biodiversidade, com destaque para o Sistema Nacional de Unidades de Conservação (SNUC), criado em 2000 (Lei 9985/2000).

No caso específico da categoria "parque", foco da pesquisa, o SNUC vem ratificar modelos de proteção externos, ao estabelecer um nível de proteção "integral", ancorado em uma perspectiva preservacionista de separação sociedade versus natureza. Tal perspectiva, que ganhou relevância nos EUA, no final do século XIX e início do século XX e se disseminou por vários países, prevê a proteção de áreas com atributos ecológicos relevantes e de grande endemismo e a proibição da permanência 
de residentes dentro da área do parque e do uso/exploração de seus recursos naturais, salvo atividades de pesquisa, educação ambiental e turismo.

Importante ressaltar que, no Brasil, muitos dos territórios transformados em unidades de conservação não se constituíam em "vazios" demográficos, cobertos de florestas "virgens" - ideia ideologicamente construída nos EUA. Esses territórios eram, em muitos casos, habitados por diferentes populações. Como resultado, em muitas iniciativas de implantação de áreas dedicadas à proteção da biodiversidade, verificou-se a sobreposição de diferentes territórios e exercícios de territorialidade sob um mesmo recorte espacial, responsável por motivar o surgimento de mudanças sociais e conflitos diversos, amplificando, assim, os propósitos de proteção da natureza e desenvolvimento socioambiental.

O contexto do Parque Nacional da Serra do Cipó, MG (PARNASC) é representativo nesse sentido. Localizado na região central de Minas Gerais, mais especificamente na Serra do Cipó, na porção meridional da Serra do Espinhaço (Figura 1), sua criação ${ }^{1}$, coordenada à época pelo Instituto Brasileiro de Desenvolvimento Florestal (IBDF) - e sob forte pressão do setor acadêmico-científico, foi efetivada em 1984, através do Decreto $n^{\circ} 90.223$ de 25/09/1984. Entre as justificativas, pode-se citar a necessidade de proteção da fauna e flora da Cadeia do Espinhaço, e particularmente da Serra do Cipó, devido ao alto grau de endemismo de suas espécies; proteção da bacia de captação do rio Cipó e preservação das belezas cênicas da região, que vinham sendo ameaçadas por queimadas para a formação de pastos, extrativismo de plantas ornamentais e de madeira para lenha e produção de carvão (Brasil, 2007). 


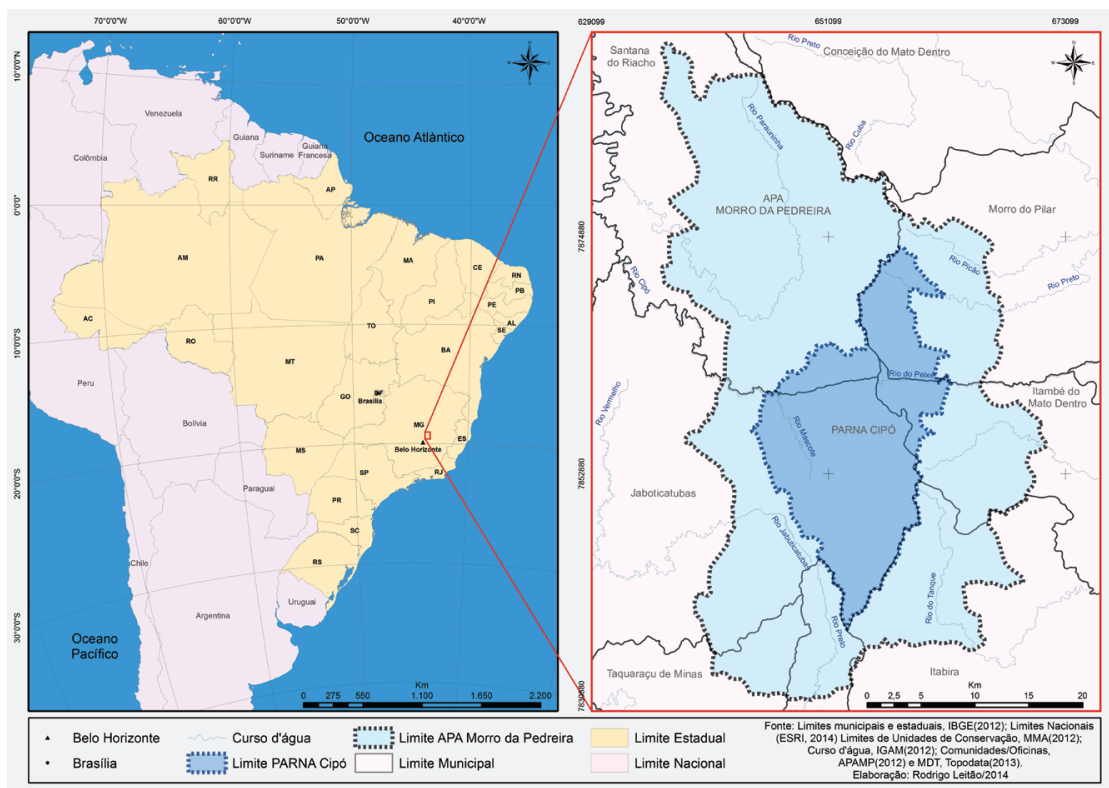

Figura 1 - Mapa Localização do Parque Nacional da Serra do Cipó

Fonte: IBGE (2012), ESRI (2014), MMA (2012), IGAM (2012), APAMP (2012), Topodata (2013). Elaborada por Rodrigo Leitão (2014).

A criação do PARNASC constituiu uma importante iniciativa voltada à proteção da biodiversidade do Espinhaço, mas também acabou interferindo diretamente em sua dinâmica socioespacial, imprimindo mudanças na estrutura social e política da região, representadas por conflitos em relação ao uso e ocupação do solo, regularização fundiária, incremento de infraestrutura de acesso e de serviços, surgimento de novas atividades econômicas como o turismo, interferências nos processos identitários de grupos sociais.

Como retratado em Sancho (2016), por exemplo, tal processo foi ancorado em uma concepção externa de proteção ambiental, concretizada "de cima para baixo" e alheia (ou pouco sensível) aos interesses e opiniões dos habitantes da região. A adoção de uma postura distanciada e pouco aberta ao diálogo por parte do órgão ambiental resultou, à época, na sobreposição e em choques com exercícios de territorialidade préexistentes, com prevalência evidente da territorialidade do Estado. A 
imposição de uma lógica unidirecional e unilateral de proteção, ancorada no impedimento da permanência de núcleos populacionais, acarretou em muitos processos de desterritorialização.

Cumpre mencionar que, mesmo que o plano de manejo do PARNASC (Brasil, 2009) destaque que, quando da criação dessa UC, mais de 50\% de seu passivo fundiário já estivesse regularizado (conjuntura até então inédita no país), não se pode desconsiderar a condição de injustiça social a que foram submetidos muitos moradores da região que não tiveram suas situações devidamente solucionadas.

Isso porque, em 1987, com a publicação do Decreto n. 94.984 de 30/09/87, teve início o processo de desapropriação das terras que ainda não haviam sido adquiridas até então. Naquele momento, mudanças na legislação já não permitiam que o governo federal comprasse terras de posseiros (sem escritura), o que significou que muitos moradores tiveram “direito" apenas à indenização por benfeitorias, plantações e criações existentes. O baixo valor das indenizações resultou, dessa maneira, no pagamento de valores irrisórios, se considerados o tamanho das áreas inicialmente ocupadas, fato que comprometeu a continuidade dos exercícios de territorialidade de muitas famílias desapropriadas. Sem dinheiro suficiente para comprar novas áreas, essas pessoas tiveram que abandonar seus modos de vida tradicionais e buscar outras formas de se sustentar, na maioria dos casos, como empregados de outras fazendas ou em estabelecimentos comerciais locais.

Além dessas situações, existem aqueles moradores que alegam não ter recebido qualquer valor indenizatório até o presente momento (mesmo aqueles referentes apenas às benfeitorias), configurando um conflito fundiário que vem se arrastando ao longo dos anos. Um exemplo, nesse caso, é a desapropriação forçada a qual a família dos "Miné" foi submetida, então moradores históricos das porções mais altas da Serra do Cipó que foram incorporadas ao território do PARNASC. Seus integrantes aguardam, até hoje, o pagamento pelas terras desapropriadas em favor da criação dessa unidade de conservação, fato que impede, portanto, um desfecho para esse conflito territorial.

Diante dessa situação, o presente trabalho tem como objetivo compreender como se efetivou especificamente esse processo de desterritorialização da família dos "Miné” e quais foram as repercussões em seus exercícios de territorialidade. 
Esse trabalho, de natureza qualitativa, envolveu, em princípio, um aprofundamento teórico sobre as temáticas de unidades de conservação, território, territorialidade e conflitos territoriais, por meio da realização de pesquisas bibliográficas em livros, artigos científicos, teses e dissertações, nacionais e internacionais.

Num segundo momento, procuramos compreender de maneira mais aprofundada como se efetivou o processo de desterritorialização em estudo, por meio de pesquisas documentais e entrevistas com analistas ambientais do ICMBio e, também, entrevistas em profundidade com um membro da família "Miné".

Inicialmente, buscamos compreender melhor as características dos exercícios de territorialidade dessa família antes do processo de desapropriação, representadas por aspectos como: 1. objetivos funcionais (abrigo físico, fonte de recursos materiais e/ou meio de produção) e simbólicos (elementos que conformam a identidade territorial, ritos, símbolos) no território; 2. manifestações culturais aí desenvolvidas; 3. ritmos e temporalidades na relação com o território; 4. formas de apropriação e controle territorial e; 5 . visões e relações estabelecidas com o meio natural.

Em seguida, procuramos investigar qual a visão e o envolvimento desses sujeitos sociais no processo de criação do PARNASC e as interferências em seus exercícios de territorialidade, bem como as posições assumidas, possíveis tensões e conflitos territoriais associados e estratégias de resistência adotadas.

\section{Unidades de Conservação e conflitos territoriais}

Autores como Zhouri e Laschefski (2010) e Acselrad (2004), entre tantos outros, têm se dedicado à busca de uma melhor compreensão das tensões e conflitos decorrentes da implementação de políticas e projetos que se fazem presentes na agenda institucional brasileira, sobretudo após 1930, cujos reflexos são percebidos em diferentes regiões, sob diversas condições, alterando significativamente os processos de territorialização existentes, bem como as dinâmicas ambientais, socioculturais, econômicas e políticas associadas. Isso significa considerar alterações ou até o comprometimento das formas de uso e ocupação (i)material de territórios em virtude de uma visão específica de ordenamento que se 
impõe em certas porções do território, o que acaba desencadeando ações de resistência em favor da continuidade de determinados processos de apropriação territorial.

Configura-se assim, em muitos casos, um processo de discriminação espacial, que se manifesta na determinação do que é o território e quais são os usos permitidos, entendido por Raffestin (1993, p. 2) como "a capacidade que tem um determinado grupo de impor a um outro uma localização específica, de interditar o acesso a certas partes do território”. Ancorado em um saber científico (Little, 2002; Acselrad, 2004), a criação de unidades de conservação de proteção integral, por exemplo, tende a legitimar um discurso ortodoxo de proteção da natureza que, em sua essência, ainda aborda perifericamente os debates sobre perspectivas de proteção que vislumbrem a compatibilização da conservação e desenvolvimento socioeconômico, sobretudo, no caso de comunidades envolvidas com a implantação de unidades de conservação ou domiciliadas em suas proximidades.

Little (2002) enfatiza que o discurso ambiental preservacionista tende a classificar, nomear, categorizar as comunidades locais como “populações residentes” em virtude da criação de novas áreas protegidas, numa perspectiva que ignora a existência prévia de regimes de propriedade comum, relações afetivas com o Lugar e memórias coletivas sobre esse espaço vivido. Esse discurso faz-se valer de um poder simbólico (Bourdieu, 2002), amparado pelo saber científico, para construir e explicar uma realidade, elencar os sujeitos sociais envolvidos e definir a posição ocupada por cada um no campo de poder.

Não se trata aqui de fazer a defesa de um tipo de territorialidade em particular (postura que acaba sendo percebida em grande parte das pesquisas sobre unidades de conservação), mas evidenciar a prevalência habitual da razão instrumental do Estado sob a razão histórica² (Quijano, 1988) no debate sobre a proteção da natureza. É evidente que, em muitos casos, se não houvesse ocorrido a criação de unidades de conservação, provavelmente as características e atributos naturais de diversas regióes do país não resistiriam aos interesses do Capital e à avidez ao lucro e ao poder, cujos protagonistas são diversos: as corporações, o poder público, grandes latifundiários e, mesmo, pequenos produtores e algumas comunidades. Mas o que se questiona é a maneira como esse processo tem se concretizado, normalmente associado a inúmeras mudanças nas estruturas sociais e na 
dinâmica territorial das áreas transformadas em UC. Uma consequência muito comum tem sido o surgimento de tensões e conflitos territoriais ${ }^{3}$, caracterizados pela "sobreposição de reivindicações de diversos segmentos sociais, portadores de identidades e lógicas culturais diferenciadas, sobre o mesmo recorte espacial" (Zhouri; Laschefski, 2010, p. 23).

Acselrad (2004, p. 26), por exemplo, tece uma interpretação sobre os conflitos ambientais oposta àquela fundamentada nas ideias de consensualismo e autoritarismo ecológico:

Os conflitos ambientais envolvem segmentos sociais com modos diferenciados de apropriação, uso e significação do território, tendo origem quando, pelo menos um dos grupos, tem a continuidade das formas sociais do meio que controlam ameaçada por impactos indesejáveis - no solo, água, ar ou sistemas vivos - decorrentes do exercício das práticas de outros grupos.

Tal interpretação enfatiza, assim, uma perspectiva da questão e do debate ambientais que abrange a diversidade sociocultural e diferentes formas de exercício de territorialidades, numa perspectiva material e simbólico-cultural.

A concepção de territorialidade, adotada neste trabalho, vai justamente nessa direção, ao remeter às práticas concretas, funcionais e, também, simbólico-culturais, bem como às representações socioespaciais das quais lançam mão os sujeitos sociais (Estado, empresas, ONGs, comunidades e grupos sociais) para tentar garantir o domínio e/ou a apropriação de uma determinada porção do espaço ${ }^{4}$. A territorialidade é uma condição intrínseca aos territórios, se manifestando, segundo Raffestin (1993, p. 162), "em todas as escalas espaciais e sociais; ela é consubstancial a todas as relações e seria possível dizer que, de certa forma, é a face vivida e a face agida do poder".

Nesse sentido, o conceito de territorialidade faz menção à forma como cada sujeito ou grupo social tenta controlar, usar e se apropriar (i) materialmente de determinado território, ação essa motivada por interesses e significados específicos e permeada por um conjunto de relações e elementos materiais e simbólico-identitários.

Essa diversidade de formas de uso e significados conferidos ao território vai ser responsável, a propósito, pela consolidação de disputas por meio da imposição de formas específicas de apropriação territorial, de controle e uso de recursos. Entram em choque aí práticas ancoradas 
na ideia de eficiência, produtividade, competitividade com práticas que pressupõem outro tipo de racionalidade e de relação com o território, em termos de temporalidade, de processo histórico e atribuição de significados aos territórios. A inevitabilidade da interação dessas diferentes práticas pressupõe, então, o reconhecimento da existência do Outro e do empreendimento de estratégias de manutenção de suas visões de mundo no âmbito de relações conflituosas de poder.

No caso da criação dos parques, como consequência de uma lógica "unifuncional" que pressupõe uma noção particular de espacialidade e de uso do território (concretamente refletidas em instrumentos de gestão e intervenção territorial como plano de manejo, zoneamento, conselho gestor), ocorre, em muitos casos, a desterritorialização de populações residentes dentro dos novos limites territoriais estabelecidos, processo que compromete, parcial ou integralmente, o exercício de suas territorialidades, seu agir social, a base de sua reprodução material e simbólico-identitária e, em alguns casos, seu próprio significado de existência no mundo. Essas populações normalmente reterritorializam-se no entorno da unidade de conservação, o que representa um novo processo de territorialização, sob condições diferentes de seu antigo território, em termos de controle territorial, das relações estabelecidas com o solo, atividades produtivas, práticas socioculturais e marcos identitários. Isso porque, além da perda do referencial territorial, os grupos sociais passam a enfrentar, nesse contexto, inúmeras restrições de uso e manejo do solo e de recursos naturais, uma vez que suas atividades econômicas (extrativismo e agricultura, por exemplo) podem representar uma “ameaça à biodiversidade”, segundo a lógica de proteção da natureza do Estado. Em algumas situações, presencia-se uma interferência direta nos processos identitários desses grupos sociais, que passam a ter seu direito de autonomia comprometido, tanto em virtude da desterritorialização sofrida quanto pela modificação de costumes e modos de vida, decorrentes da "chegada" de novas atividades econômicas, como o turismo (Sancho, 2016).

Esse cenário se complexifica uma vez que o território constitui, em muitos casos, o referencial identitário desses grupos sociais. Haesbaert (2007) assinala que as identidades coletivas representam, nessas situações, a base para a conformação de uma identidade territorial, que "se caracteriza como a identidade social que toma como seu referencial central, definidor do grupo, o território” (Haesbaert, 2007, p. 44). O território 
representa, portanto, um elo identitário para o grupo, combinando de maneira indissociável, elementos materiais e simbólicos, o que implica essencialmente em reconhecer que o território "não diz respeito apenas à função ou ao ter, mas ao ser" (Bonnemaison; Cambrèzy, 1996).

No caso de muitas comunidades rurais que habitam as proximidades de recortes espaciais transformados em unidades de conservação, os vínculos territoriais existentes são ainda muito fortes, mesmo que já se considerem as influências da lógica de mercado e presença, cada vez mais marcante, de elementos do modelo urbano-capitalista de organização social, como salienta Monte-Mór (2006). Nós nos referimos aqui a territórios conformados, essencialmente, pela perspectiva da apropriação, cuja expressão de territorialidade não se traduz em títulos de propriedade, mas sim, por relações materiais e simbólico-culturais de grande significado e amplificadoras de sentimentos de identidade e de pertencimento de uma comunidade, responsáveis por fortalecer os laços e vínculos territoriais existentes.

Inspirados nessas reflexões, direcionamos um olhar mais aprofundado para a gênese do processo de desterritorialização vivenciado pela família "Miné", em virtude da implantação do PARNASC, e as repercussões em seus exercícios de territorialidade.

\section{0 conflito territorial envolvendo a família dos "Miné"}

Por meio de conversas com analistas ambientais do Parque Nacional da Serra do Cipó, tivemos acesso ao caso da desterritorialização sofrida pela família dos "Miné", uma das últimas famílias que ainda permaneciam no território do parque desde sua criação. Procuramos, então, nos aproximar e melhor entender esse conflito territorial ainda sem solução, haja vista que os filhos reivindicam até hoje, na justiça, o pagamento pelas terras e benfeitorias desapropriadas em favor do PARNASC.

Tivemos a oportunidade de realizar uma entrevista em profundidade com Sr. Esmail, 48 anos, um dos quatro filhos de Antônio Rosa dos Anjos e Odília Rosa de Araújo, conhecidos como "Miné”. Inicialmente, buscamos entender como se processavam os exercícios de territorialidade dessa família quando ainda residiam em suas terras. Em seguida, procuramos compreender como se efetivou o processo de desterritorialização envolvendo essa família e suas repercussões na manutenção de seus exercícios de territorialidade. 
Sr. Esmail nasceu na propriedade da família, localizada na região das Cachoeiras do Gavião, Andorinha e Tombador. Parte dessas terras foi herdada pelo seu pai (herança de seu bisavô), havendo também áreas que, segundo ele, foram compradas. Não existiam cercas e os limites da propriedade eram estipulados por meio de marcos paisagísticos. Outros onze irmãos de seu pai também herdaram terras na mesma região e todos se dedicavam à lavoura (cana, mandioca, arroz, feijão, banana) e às criações (gado, porcos, galinha). Segundo as falas de Esmail, a noção de propriedade era muito bem demarcada: "cada irmão de meu pai tinha sua parte", mesmo que não houvesse cercas ou outros instrumentos de delimitação territorial. Existiam também áreas comuns, "nos altos da Serra”, compartilhadas por todos, sobretudo para a criação extensiva de gado. Não havia qualquer regulação desses usos. O respeito era o princípio que regia as relações e usos materiais do território. As "trocas de dia", nos períodos de formação de lavouras e colheitas, também eram muito comuns. Contudo, essa prática, muito mais do que evidenciar as relações de solidariedade entre os vizinhos, parecia representar uma espécie de "moeda de troca”, já que essa "ajuda" recebida implicava, obrigatoriamente, em um compromisso futuro de retribuição dos mesmos dias trabalhados.

Esmail passou toda sua infância na roça, dividindo-se entre o auxílio ao pai nas obrigações cotidianas e, os estudos, em Cardeal Mota. Após terminar a $3^{\mathrm{a}}$ série, deixou de estudar para se dedicar inteiramente às atividades na propriedade da família. Se lembra, na infância, das tropas que cruzavam a Serra, nos tempos dos avós, transportando rapadura em lombo de burro. Os tropeiros, segundo o entrevistado, representavam, juntamente com um estabelecimento comercial local - a Venda do Zeca -, os únicos "veículos de informação", "atualizando" os moradores sobre aquilo que acontecia fora da serra. Naquela época, não existia relógio, o tempo era o tempo da "lida da roça" e o canto do galo anunciava o início do dia, costume muito comum entre os pequenos agricultores da serra. Os momentos de descanso e de lazer se resumiam às visitas aos vizinhos, para conversar e fazer a novena. Além disso, era costume se frequentar a missa uma vez por mês na Fazenda Cipó, importante fazenda da região.

Assim como outros moradores da Serra do Cipó, Esmail e sua família consumiam praticamente tudo o que plantavam. O pouco que sobrava era vendido ou trocado na Venda do Zeca. O extrativismo das "flores secas" representava a principal fonte de recursos, comercializadas 
com vendedores de Diamantina e Congonhas. Esmail nos relatou que as enfermidades eram "curadas" com chá do mato, prática também comum, mas citou ainda que muitos moradores tinham o costume de procurar ajuda com Dona Lerinda, matriarca da Fazenda Cipó. Essa senhora possuía um livro sobre medicina que auxiliava na indicação do tratamento de muitas doenças.

Para Esmail, o significado ou os sentidos de natureza retratam uma relação de dependência, na qual os atributos naturais constituíam fonte de subsistência e garantia de qualidade de vida, essencial às suas práticas materiais: "A natureza é boa... as plantas, área verde... A gente plantava, morava nos lugares que cultivava, bebia água boa, preservada...”. Por isso mesmo, foi enfático ao afirmar que não havia o costume de desmatar, mas sim uma preocupação em reservar áreas de mata: "Naquela época, havia mata... só plantávamos em lugares que podia... tinha a preocupação com as cabeceiras das águas... queimava só os campos...”. Existia, segundo o entrevistado, a prática da retirada de árvores apenas para consumo próprio, como o "vinhato" [vinhático], sucupira, pau monjolo, pindaíba e candeia para a construção de casas e de cercas. Esse hábito implicava, segundo o entrevistado, em um baixo impacto sobre esses atributos naturais. Um costume muito peculiar entre os moradores do alto da serra era a utilização da candeia para a iluminação: "a candeia a gente rachava, lascava e iluminava", costume esse que se perdeu na atualidade, diante das proibições impostas pelos órgãos ambientais na região, nas últimas décadas e, também, pela chegada da iluminação elétrica nas áreas mais isoladas da serra.

Esmail afirmou também que antes da criação do parque, havia "muitos bichos" na região e a caça representava um hábito muito presente nos modos de vida: "De todo lado caçava, toda a vida... Hoje não pode mais!”. Com a chegada do IBAMA (Instituto Brasileiro do Meio Ambiente e dos Recursos Naturais Renováveis), “os bichos sumiram”, percepção recorrente em outras entrevistas realizadas com moradores antigos das áreas mais altas da Serra do Cipó, de que, com o fim das plantações, os bichos passaram a migrar para outras regióes em busca de alimento.

O Sr. Esmail reconhece a importância da política do governo que estabelece a criação de áreas específicas para a proteção de atributos naturais, mas questiona a forma como o processo foi conduzido no caso do PARNASC, muito distante dos moradores, impositivamente e sem o devido ressarcimento pela desapropriação devida: 
Ia nas casas, conversava...falavam que ia criar... “inventou”! Aí mediram a terra, contava os animais...as plantas....

Melhora de um lado...bom pra preservar a natureza...por outro, não pagaram a gente....

Em vários momentos da entrevista, ele fez referência ao não recebimento da indenização em virtude da incorporação de toda a propriedade de sua família aos limites do parque. "Não recebemos! Viram as plantas, criação, casa... Não sei o valor...”. Diante do não recebimento dos valores correspondentes à desapropriação, Sr. Esmail, seus pais e irmãos permaneceram nas terras e continuaram a desempenhar suas atividades normalmente. Contudo, a presença deles dentro do território do parque não constituía o único ponto de conflito. Na verdade, como residiam nas proximidades de três importantes cachoeiras da região - Andorinha, Gavião e Tombador - essa família tinha o hábito de cobrar dos turistas uma taxa para passar dentro de sua propriedade e acessar as cachoeiras:

Nois [sic] cobrava os turistas na passagem para as Andorinhas... era pra ajudar nois, passava dentro da nossa terra...a gente ajudava, arrumava estrada...uma vez salvamos uns turistas...passamos a noite toda por causa de uma tromba d'água....

Essa situação incomodava a então gestão do PARNASC, segundo relatos de um dos analistas ambientais do ICMBio, já que alguns turistas reclamavam que tinham que pagar duas vezes para visitar o parque. Esse conflito foi se estendendo até 2006, quando, após a morte de sua mãe, Dona Odília (o pai já havia falecido), os três irmãos foram desapropriados. As Figuras 2 e 3, a seguir, retratam a casa da família antes e depois da desapropriação. 


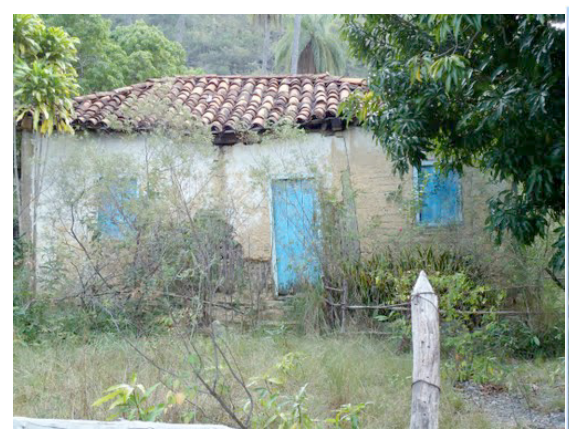

Figura 2 - Foto antiga da casa de Esmail.

Fonte: Leandro Durães (1998).

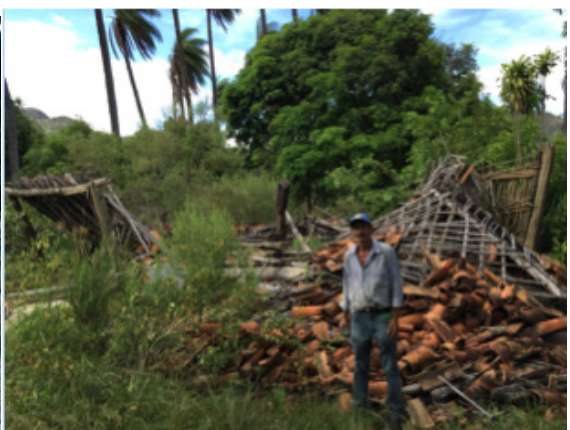

Figura 3 - Destroços da casa de Esmai antes da desapropriação Fonte: Altair Sancho (2015).

Aqui, parece fundamental chamar a atenção para a maneira como tal processo de desapropriação foi conduzido: a posição institucional aponta que o fato de um dos irmãos ter sido acusado de tentativa de estupro a uma turista foi a "deixa” para a determinação judicial de retirada da família do território do PARNASC, pois a imissão na posse ao IBAMA foi determinada pela Justiça. Já segundo o relato do Sr. Esmail, o chefe do Parque na época, juntamente com um advogado,
arrumou a desapropriação... Arrumou um truque pra tirar a gente... Depois que mamãe morreu, foram lá com a polícia federal... falamos que não podíamos sair, somos nascidos e criados aqui... não tinha dinheiro... Levaram o documento de desapropriação... pegaram nossas coisas e trouxeram pra barreira... ficamos mais de dois anos vivendo na beira da estrada de qualquer jeito, bebendo água ruim, cheia de cloro... adoecemos tudo...

Os irmãos foram, conforme relato, despejados e alocados em uma barreira da polícia rodoviária estadual, às margens da rodovia MG-010. Depois de "residirem" ali por mais de dois anos em condições precárias, subumanas e de grande insegurança, os irmãos receberam uma casa em um lote no bairro Cerrado (Figuras 4 e 5), no Distrito de Serra do Cipó. De acordo com Sr. Esmail, sua situação e de seus irmãos é muito difícil. A todo o momento lamenta não poder ter condições de voltar a viver no campo e retomar suas atividades: "se tivesse um terreno grande, bom, com água boa pra fazer lavoura... não estamos dando mais conta de viver aqui”. 


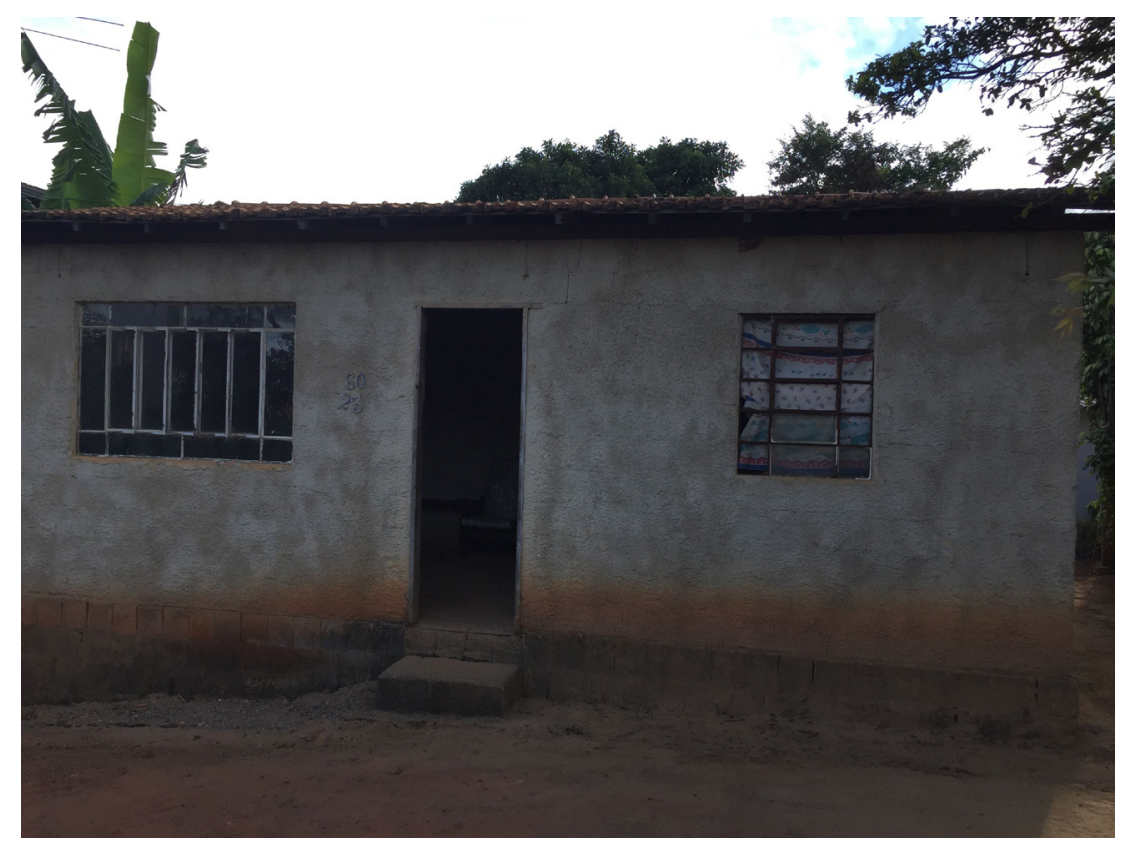




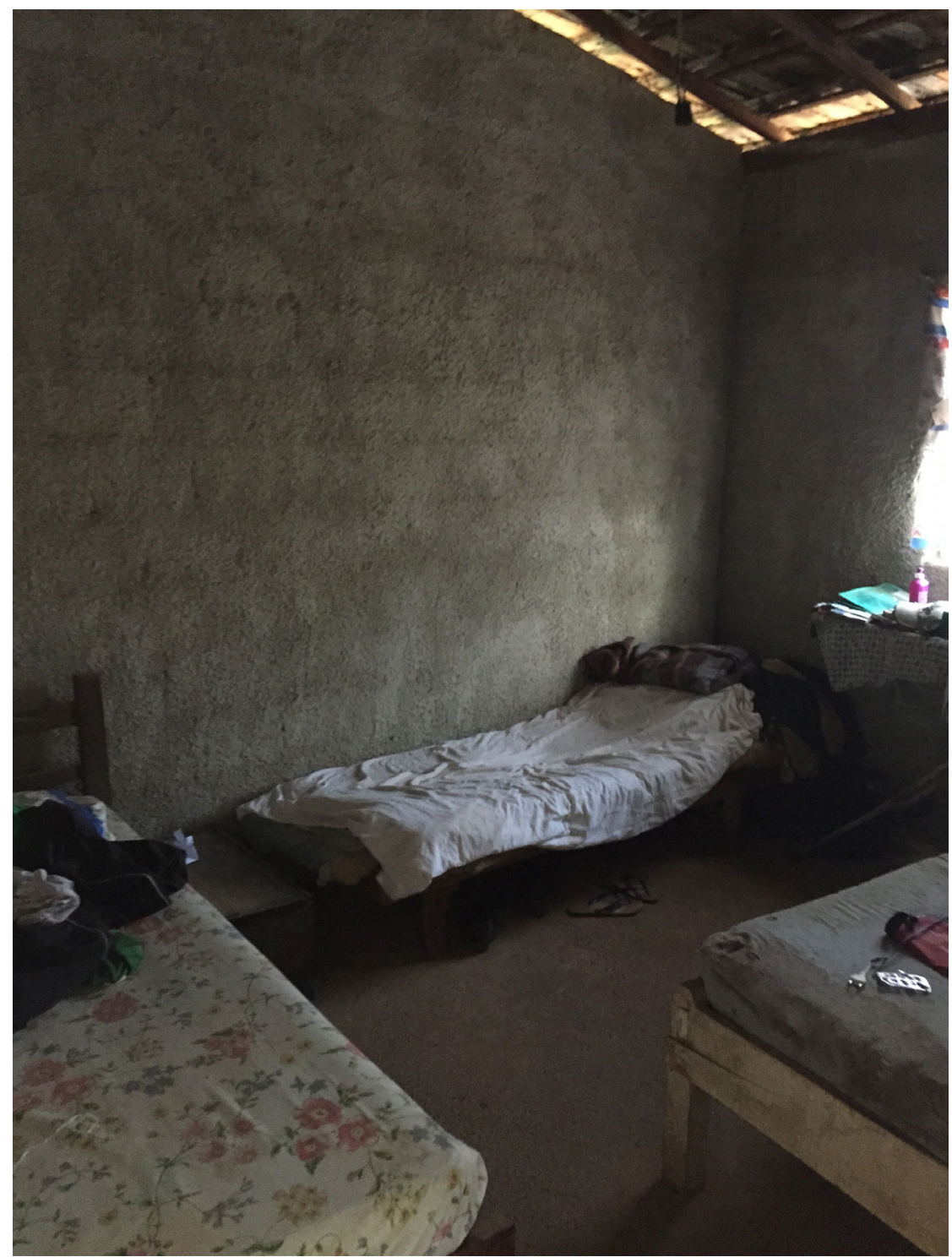

Figuras 4 e 5 - Casa onde residem o Sr. Esmail e seus irmãos (Loteamento Cerrado, Distrito da Serra do Cipó, município de Santana do Riacho) 
No plano de manejo do PARNASC, publicado em 2009, tal situação é referenciada, mas de uma forma que não dá conta de retratar com profundidade tal processo, assumindo uma perspectiva extremamente simplificadora:

No momento resta um único e pequeno foco de conflito, na região denominada Bocaina, onde permanecem habitadas 6 casas. $\mathrm{O}$ principal conflito, na área antes ocupada pela família de D. Odília, conhecidos por "Miné", encerrou-se com a retirada dos últimos três ocupantes da área em 2006, por ordem judicial. Aproxima-se o momento em que todos deverão sair, a menos que alguns possam permanecer por razões de saúde, ainda que devidamente indenizados e sem direito de sucessão. Esta eventualidade está prevista no zoneamento do Parque (encarte 4), caso sejam devidamente comprovadas as necessidades médicas, com a delimitação de duas “zonas de ocupação temporária (ZOT)”(Brasil, 2009, p. 314).

Ancorado em uma perspectiva legal e sob a prerrogativa de cumprimento de uma "ordem judicial", uma versão da realidade - a do ICMBio - se sobrepôs ao argumento defendido pela família dos "Miné”, já que eles alegam, até hoje, o não recebimento de indenização. Nesse caso, o poder do Estado prevaleceu, conformando um determinado tipo de territorialidade que ratifica uma ordem de proteção da natureza alicerçada no impedimento da presença de moradores dentro do território do Parque.

O que nos chama a atenção nesse caso é a maneira brutal e desrespeitosa como tal processo foi conduzido. Segundo Esmail, "eles chegaram, avisaram que não poderíamos continuar... foram colocando nossas coisas na caminhonete e levaram a gente pra barreira", na MG-010. Assim, a criação do PARNASC representou na vida desses irmãos um processo traumático de desterritorialização, no qual seus vínculos territoriais foram bruscamente rompidos, comprometendo-se a continuidade de seus exercícios de territorialidade. Nesse caso, não estamos tratando apenas do comprometimento de condições materiais de reprodução de seus modos de vida, mas, também, de processos de significação identitária e de pertencimento, da maneira como se percebiam e se relacionavam no/com o mundo, seu sentido de existência.

O não pagamento da indenização acirrou ainda mais os efeitos desse processo, já que os irmãos se viram impossibilitados de se reterritorializar por meio da aquisição de um novo "pedaço de terra”. Deixar seu território e, por consequência, abandonar suas práticas (i)materiais para serem 
obrigados a conviver com uma nova realidade - residir em uma casa semiacabada, em um terreno de $250 \mathrm{~m} 2$ na área urbana do Distrito da Serra do Cipó e em condições precárias - trouxe consequências diretas às suas condições de sujeito:

Ficou complicado... Lugar igual aquele... Aqui embaixo... olha pra você vê! Igual lá, a água, os vizinhos, tinha como plantar, criação..."

"As rezas nos vizinhos não tem mais... naquele tempo era muito melhor... tinha o pessoal mais antigo".

“Tinha vontade de voltar... ou pagassem pra comprar outro lugar....

Para o entrevistado, o recebimento da indenização possibilitaria que ele e seus irmãos adquirissem outra terra para, então, retomar suas atividades e modos de vida, mesmo que em novas condições. Fica evidente, no caso de Esmail, sua dependência (i)material em relação a seu antigo território. Atualmente, Esmail depende de "bicos" e de oportunidades esporádicas de trabalho para sobreviver, contando, muitas vezes, com ajudas e doações de vizinhos. Um de seus irmãos encontra-se em estado delicado de saúde, impossibilitado de trabalhar, enquanto outro está envolvido com drogas (crack).

\section{Considerações finais}

A aproximação e melhor compreensão do conflito territorial envolvendo a família de agricultores "Miné" e a gestão do Parque Nacional da Serra do Cipó no ano de 2006 evidenciou um exemplo claro de um processo de discriminação espacial (Raffestin, 1993) e de prevalência da razão instrumental do Estado (Quijano, 1988) sobre demais "razões" então existentes. A perspectiva de proteção ambiental privilegiada no caso da implantação do PARNASC foi responsável por acarretar inúmeras transformações nas estruturas sociais e na dinâmica territorial da Serra do Cipó, com graves prejuízos aos modos de vida tradicionais de muitos agricultores familiares. Esse projeto estatal de (des)ordenamento territorial ignorou, portanto, a existência prévia de modos de vida, relações afetivas, vínculos e memórias desses agricultores em relação ao espaço vivido. Os poucos moradores que resistiram e conseguiram permanecer em seus territórios, como o caso por nós retratado da família dos "Miné”, passaram 
a viver em uma situação de conflito com os novos regramentos de uso impostos pelo órgão ambiental.

Causou-nos grande perplexidade como se deu o desfecho do conflito envolvendo essa família quando da imissão de posse, por parte do ICMBio. Os irmãos que ainda resistiam foram expulsos compulsoriamente de suas terras, sem direito à defesa e foram literalmente "depositados" em um posto fiscal abandonado, às margens da rodovia MG-010. Essa ação truculenta, ocorrida em 2006, chocou a população do Distrito da Serra do Cipó e trouxe à tona lembranças e memórias de um passado em que a ordem de proteção da natureza estava ainda alicerçada em práticas distanciadas da realidade e das demandas locais.

As situações observadas nos permitem concluir que muitas das repercussões negativas do processo de criação do PARNASC poderiam ter sido minimizadas e, até mesmo, evitadas caso a postura do órgão ambiental, à época, tivesse sido diferente. Estamos, aqui, nos referindo à maneira autoritária como tal processo foi conduzido, extremamente dissociado das demandas locais, em função da adoção de uma concepção singular e externa de proteção, ancorada na ideia de separação entre Homem e Natureza e, sobretudo, ao não pagamento de todas as indenizações devidas. Esse cenário resultou não apenas em situações de injustiça ambiental, como aquela da família dos "Miné”, mas também na construção de um imaginário negativo em relação ao ICMBio, associado a uma perspectiva essencialmente punitiva, fiscalizatória, fechada ao diálogo e à construção de parcerias.

As circunstâncias desse processo são sentidas até o presente momento, seja na tentativa de cumprimento dos objetivos de proteção da biodiversidade da Serra do Cipó, seja na construção de práticas de governança mais democráticas e participativas, capazes de alicerçar parcerias e potencializar o papel do PARNASC na consolidação de processos de desenvolvimento socioambiental nessa região.

Avançar nessa direção implica, por exemplo, que a gestão do parque reconheça os modos de vida tradicionais e respectivas práticas culturais (i)materiais enquanto parte integrante do rico patrimônio paisagístico da Serra do Cipó e que, portanto, também precisam ser alvo de iniciativas de proteção e valorização, numa perspectiva que rompe com modelos de conservação que ainda insistem em interpretar as dimensões natural e cultural de maneira separada e até mesmo contraditórias. 


\section{Notas}

1 Cumpre mencionar que em 1984 ocorreu o processo de federalização desta Unidade de Conservação, o então Parque Estadual da Serra do Cipó, criado em 1975 no âmbito da Lei Estadual n 6.605 de 14/07/75.

2 A razão histórica, embora subordinada à razão instrumental, continua possuindo uma forte presença entre os povos marginalizados pelos sistemas atuais de poder e age "contra o poder existente" (Quijano, 1988 apud Litlle, 2002, p. 17). Estão ancoradas em regime de propriedade comum, com reconhecido sentido de pertencimento a um lugar específico e profundidade histórica da ocupação guardada na memória coletiva.

3 Os autores identificam três tipos de conflitos ambientais: distributivos, espaciais e territoriais.

4 O conceito de territorialidade, de acordo com Haesbaert (2007), reúne, ainda, outras interpretações: 1 . mais associada aos aspectos simbólico-culturais, ou; 2. denotando uma noção mais abstrata, num sentido epistemológico, ou; 3. referente à materialidade dos exercícios de territorialidade.

\section{Referências}

ACSELRAD, H. Conflitos Ambientais no Brasil. Rio de Janeiro: Relume Dumará, 2004.

BONNEMAISON, J. ; CAMBRÈZY, L. Le lien territorial: entre frontières et identités., Paris: L’Hartmattan, 1996. (Géographies et Cultures; Le Territoire). Tomo I.

BOURDIEU, P. O poder simbólico. 5. ed. Rio de Janeiro: Bertrand Brasil, 2002.

BRASIL. Decreto 90.223, de 25 de setembro de 1984. Cria, no Estado de Minas Gerais, o Parque Nacional da Serra Do Cipó e dá outras providências. Brasília, DF, set. 1984.

. Decreto $n^{\circ}$ 94.984, de 30 de Setembro de 1987. Declara de utilidadepública, para fíns de desapropriação, áreas de terras e benfeitorias, integrantes do perímetro abrangido pelo Decreto $\mathrm{n}^{\circ}$ 90.223, de 25 de setembro de 1984. Brasília, DF, set. 1987.

. Lei 9.985, de 18 de julho de 2000. Sistema Nacional de Unidades de Conservação - SNUC, 2000.

. Ministério do Meio Ambiente. Instituto Chico Mendes de Conservação da Biodiversidade. Plano de Manejo do Parque Nacional da Serra do Cipó e da APA Morro da Pedreira. Relatório da Oficina de Planejamento. Cardeal Mota, Minas Gerais: MMA, 2007.

. Ministério do Meio Ambiente. Instituto Chico Mendes de Conservação da Biōiversidade. Plano de Manejo: Parque Nacional da Serra do Cipó - Área de Proteção Ambiental Morro da Pedreira. Brasília: MMA, 2009. 
BRYANT, R.; BAILEY, S. A politicised environment. In: .Third World Political Ecology. London/New York: Routledge, 1997.

DIEGUES, A. C. O Mito Moderno da Natureza Intocada. São Paulo: EDUSP, 1994. HAESBAERT, R. Território e Multiterritorialidade: um debate. GEOgraphia, ano IX, n.17, 2007.

LITLLE, P. Territórios Sociais e Povos Tradicionais no Brasil: por uma antropologia da territorialidade. Série Antropologia, n. 322. Brasília: Departamento de Antropologia, 2002.

MINAS GERAIS. Lei n. 6.605, de 14 de julho de 1975. Autoriza o Poder Executivo a criar o Parque Estadual da Serra do Cipó. Belo Horizonte, MG, jul. De 1975.

MONTE-MÓR, R. L. As teorias urbanas e o planejamento urbano no Brasil. In: DINIZ, C.; CROCCO, M. A. (Ed.) Economia Regional e Urbana: contribuições teóricas recentes. Belo Horizonte: Editora UFMG, 2006.

QUIJANO, A. Modernidad, identidad y utopia en América Latina. Lima: Sociedade e Política Ediciones, 1988.

RAfFeStin, C. Por uma Geografia do Poder. São Paulo: Ática, 1993.

SANCHO, A. Des-ordenamento territorial e unidades de conservação. 2016. $460 \mathrm{f}$. Tese (Doutorado em Geografia) - Programa de Pós-Graduação do Departamento de Geografia, Universidade Federal de Minas Gerais, Belo Horizonte, 2016.

ZHOURI, A.; LASCHEFSKI, K. Desenvolvimento e Conflitos Ambientais. Belo Horizonte: Editora da UFMG, 2010.

Altair Sancho Pivoto dos Santos - possui graduação em Turismo pela Universidade Federal de Juiz de Fora (UFJF). Mestrado em Psicossociologia de Comunidades e Ecologia Social pela Universidade Federal do Rio de Janeiro e Doutorado em Geografia pela Universidade Federal de Minas Gerais. Atualmente é Professor e Pesquisador do Curso de Turismo da Universidade Federal de Juiz de Fora. 